\title{
Bioremediation of Diesel Oil Contaminated Soil by a Novel Isolated Potential Oil Degrading Staphylococcus argenteus MG2 Bacteria Using Biostimulation Method
}

\author{
Mahima Golani*† and Krishnan Hajela** \\ *PMB Gujarati Science College, Indore, M.P., India \\ **School of Life Sciences, Devi Ahilya University, Indore, M.P., India \\ †Corresponding author: Mahima Golani; go.mahi@yahoo.com
}

Nat. Env. \& Poll. Tech.

Website: www.neptjournal.com

Received: $28-12-2019$

Revised: $16-01-2020$

Accepted: 01-02-2020

\section{Key Words:}

Bioremediation

Diesel oil

Hydrocarbons

Oil degradation

Biostimulation

Staphylococcus argenteus MG2

\begin{abstract}
The potential oil-degrading isolate Staphylococcus argenteus MG2 was used for bioremediation of oil-contaminated soil. Hydrocarbon degradation by the soil microorganisms was evaluated in a soil experimentally contaminated with diesel oil. The effects of six different biological treatments on hydrocarbon degradation were determined during a 50 days incubation period to evaluate biostimulation via inorganic fertilizers (NPK) or manure (compost) with and without inoculum of Staphylococcus argenteus MG2. Eight soil samples were used: (S) uncontaminated control soil; (CS) contaminated soil; (CSF) contaminated soil + N-P-K fertilizer; (CSC) contaminated soil + compost; (CSI) contaminated soil + Inoculum; (CSFI) contaminated soil + N-P-K fertilizer + Inoculum; (CSCl) contaminated soil + compost + Inoculum; (SCSCI) sterile (oil) contaminated soil + compost + Inoculum. Percentage of oil degradation during bioremediation treatment of 50 days was found to be (CS) $-32 \%$, (CSF) $-70.80 \%$, (CSC) - 75\%, (CSI) - 84.40\%, (CSFI) - 91\%, (CSCI) - 93\%, (SCSCI) - 94\% respectively. Results showed that not only inorganic nutrients NPK and compost stimulated hydrocarbon biodegradation but inoculation of Staphylococcus argenteus MG2 also enhanced hydrocarbon degradation. The microbial count was found to be higher in SCSCI soil sample. The germination percentage and growth of leguminous plant (Vigna radiata) in the treated soil was also notably greater. It may be concluded that the Staphylococcus argenteus MG2 bacteria possess remarkable oil-degrading properties and can be effectively employed in the bioremediation of oil-contaminated soils and can be used for agriculture purpose.
\end{abstract}

\section{INTRODUCTION}

The pollution of soil by petroleum products has become a widespread problem and among the technologies available to deal with contaminated soils, bioremediation based on the metabolic activities of microorganisms has certain advantages (Van Gestel et al. 2003). The useful properties of the soil such as soil fertility, water holding capacity, permeability and binding capacity get lost due to the contamination of soil by oil (Vasanthavigar et al. 2010). Microbial bioremediation is the only way to preserve our nature to overcome these environmental problems (Chithra et al. 2014). Lipase producing strains played a key role in the enzymological remediation of polluted soil (Lin et al. 2012). In bioremediation process, lipase is a new aspect in environmental management (Nakamura et al. 1994). Bioremediation is emerging as the cost-effective treatment method for the hydrocarbon contaminated soil (Namkoong et al. 2002). Bioremediation has become an important aspect among different treatment techniques for removal of polyaromatic hydrocarbons and its biodegradation was achieved either by bacteria (Arulazhagan \& Vasudevan
2011, Hamamura et al. 2013), fungi (Hadibarata et al. 2009, Cerniglia \& Sutherland 2010) or algae (Munoz et al. 2003, Chan et al. 2006).

Bioremediation of hydrocarbon contaminated soils exploit the ability of microorganisms to degrade the organic contamination which has been established as an efficient, economic, versatile and environmentally sound treatment (Norris et al. 1994). The most applicable bioremediation process is biostimulation of the indigenous microorganisms by addition of nutrients, as the input of large quantities of carbon sources cause a rapid loss of the available pools of major inorganic nutrients, such as $\mathrm{N}$ and $\mathrm{P}$ (Morgan et al. 1989). In various studies, the effects of biostimulation with mainly NPK fertilizers have reported positive effects on oil decontamination in cold ecosystems (Atlas 1981, Margesin \& Schinner 1999a). Ex-situ treatment method can help in the clean-up of diesel contaminated soil sites (Thilakar et al. 2013). Compost and inorganic nutrients like $\mathrm{N}$ and $\mathrm{P}$ stimulated hydrocarbon biodegradation. Lipase activity was found to be the most applicable parameter for analysing the 
hydrocarbon degradation in soil (Riffaldi et al. 2006). Recent research works have shown that lipase is closely related to the organic pollutants present in the soil. Total hydrocarbons from contaminated soil got substantially reduced due to lipase activity. Research undertaken in this area is likely to progress the knowledge in the bioremediation of oils spill (Margesin \& Schinner 1999a, Riffaldi et al. 2006).

The objectives of this study were to isolate a potential oil-degrading strain which could be used in bioremediation of oil-contaminated sites and to find out the efficiency of the microbial isolates during the bioremediation process. This was achieved by evaluating six biological treatments of soil consisting in biostimulation via inorganic fertilizers (NPK) or manure (compost) with and without inoculum of Staphylococcus argenteus MG2 a potential lipase producing bacterium. Hydrocarbon degradation by the indigenous soil microorganisms along with oil-degrading bacteria and fertilizers was evaluated in a soil experimentally contaminated with diesel oil. The germination percentage and growth of a fast-growing leguminous plant (Vigna radiata) in the treated soil was also observed.

\section{MATERIALS AND METHODS}

\section{Screening of Lipase Producing Bacteria}

The screening of lipolytic bacteria was done by enrichment culture technique from different samples in Tributyrin medium containing $0.5 \%(\mathrm{w} / \mathrm{v})$ peptone, $0.3 \%(\mathrm{w} / \mathrm{v})$ yeast extract, $1 \%(\mathrm{v} / \mathrm{v})$ Tributyrin. The lipolytic activity of isolated colonies was observed by spot inoculation on Tributyrin agar medium plates and incubated at $37^{\circ} \mathrm{C}$ for $48 \mathrm{~h}(\mathrm{pH}-7 \&$ 9) and zone of clearance was observed due to hydrolysis of tributyrin by lipase (Golani et al. 2019).

\section{Identification of Selected Isolate}

The selected bacterial isolate MG2 was identified following the criteria laid down by Bergey's Manual of Determinative Bacteriology (Holt et al. 1994) and the biochemical tests. The isolate was further identified up to species level and confirmed based on 1500bp of $16 \mathrm{~S}$ rDNA gene sequence analysis by Microbial Type Culture Collection Centre and Gene Bank (MTCC), Institute of Microbial Technology, (IMTECH), Chandigarh, India and culture was deposited also. The 16S rDNA nucleotide sequence of the isolate MG2 determined in this study has been deposited in the (NCBI, US) Gene Bank database.

\section{Collection of Soil Sample}

The soil sample was collected from the Botanical garden of Nasia Road, Indore. The characteristic features of the soil were analysed.

\section{Design of Bioremediation Experiments}

Eight pans were prepared, each containing $1 \mathrm{~kg}$ of sieved soil at $50 \%$ of its water holding capacity (WHC); each pan, except treatment $\mathrm{S}$, was spiked at $10 \mathrm{~g}$ of diesel oil $/ \mathrm{kg}$ soil and treated as follows:

Two pans were taken as controls:

1. S (control): uncontaminated soil (Soil without oil): this pan was used to monitor the level of biological activities in soil.

2. CS (contaminated soil): in this pan, only oil was added and contained no further addition to evaluate hydrocarbon degradation by the indigenous soil microorganisms.

Rest of six pans were used for bioremediation treatments:

3. CSF: this pan was treated with $\mathrm{N}, \mathrm{P}$ and $\mathrm{K}$ nutrients, added as $0.5 \mathrm{~g}\left(\mathrm{NH}_{4}\right) \mathrm{H}_{2} \mathrm{PO}_{4}$ and $2.5 \mathrm{~g} \mathrm{KNO}_{3} / \mathrm{kg}$ soil at a $\mathrm{C}: \mathrm{N}: \mathrm{P}: \mathrm{K}$ ratio in the soil of $4: 1: 0.16: 0.84$.

4. CSC: this pan was added with $50 \mathrm{~g}$ of manure compost from Indore Biotech plant $\mathrm{kg}^{-1}$ soil on the dry weight basis. The compost had a pH of 7.8 and contained $17.2 \%$ organic $\mathrm{C}, 9.9 \mathrm{mg} . \mathrm{g}^{-1}$ nitrogen and $2.8 \mathrm{mg} \cdot \mathrm{g}^{-1}$ phosphorus.

5. CSI: this pan was inoculated with $10 \mathrm{~mL}$ inoculum of Staphylococcus argenteus MG2 a potential lipase producing bacterium to evaluate hydrocarbon degradation by the indigenous soil microorganisms along with oil-degrading bacteria.

6. CSFI: this pan was treated with $\mathrm{N}, \mathrm{P}$ and $\mathrm{K}$ nutrients,

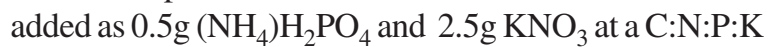
ratio in the soil of 4:1:0.16:0.84 and was inoculated with $10 \mathrm{~mL}$ inoculum of Staphylococcus argenteus MG2 to evaluate hydrocarbon degradation by the indigenous soil microorganisms along with oil-degrading bacteria and chemical fertilizers.

7. CSCI: this pan was added with $50 \mathrm{~g}$ of manure compost from Indore Biotech plant $\mathrm{kg}^{-} 1$ soil on the dry weight basis and was inoculated with $10 \mathrm{~mL}$ inoculum of Staphylococcus argenteus MG2 to evaluate hydrocarbon degradation by the indigenous soil microorganisms along with oil-degrading bacteria and biological fertilizers.

8. SCSCI: soil of this pan was sterilized to kill the soil indigenous microorganisms and then was added with 50 $\mathrm{g}$ of manure compost from Indore Biotech plant kg ${ }^{-1}$ soil on a dry weight basis and was inoculated with $10 \mathrm{~mL}$ inoculum of Staphylococcus argenteus MG2 a potential lipase producing bacterium to evaluate hydrocarbon degradation with inoculated oil-degrading bacteria and biological fertilizers.

The pans were incubated in the dark at $25^{\circ} \mathrm{C}$ for 50 days. 
The water content of the pans was adjusted and maintained at $50 \%$ of the WHC during the whole incubation period. Pan contents were thoroughly mixed on every second day for assurance of sufficient aerobic condition.

Chemical and biological analyses were performed at the end of 10,20,35, 50 days by sampling 3 soil subsamples from each pan (Riffaldi et al. 2006).

\section{Chemical Analysis}

Soil pH: $10 \mathrm{~g}$ of soil sample was collected from each experimental pot after completion of their treatment period and mixed with sterile distilled water in a beaker stirred and allowed to stand for 30 minutes. The soil $\mathrm{pH}$ was then determined with a glass electrode of digital $\mathrm{pH}$ meter.

Total petroleum hydrocarbons content (estimation of the percentage of diesel oil): Diesel oil degradation from each experimental pot soil except control after completion of their treatment period was studied by gravimetric analysis (Chang 1998, Marquez-Rocha et al. 2001). One g of the soil was taken from each pot. Petroleum ether and acetone were taken in the ratio $1: 1$ and mixed with the soil sample in a separating funnel. Bacterial activities were stopped by adding $1 \% 1 \mathrm{~N} \mathrm{HCl}$. The mixture was shaken for about 30 minutes and then left undisturbed for about 10 minutes. The upper solvent along with oil was separated from the lower soil extract. The solvent with the oil layer was taken in a preweighed clean beaker. The extracted oil was passed through anhydrous sodium sulphate to remove moisture. The petroleum ether and acetone were evaporated on a water bath and then kept in the hot air oven at $100^{\circ} \mathrm{C}$ for 10 minutes until the beaker gets dry. The quantity of residual oil left after biodegradation was estimated by weighing the quantity of oil in a tared beaker. The percentage of diesel oil degraded was determined from the following formula:

$\%$ of diesel oil degraded $=\frac{\text { Weight of diesel oil degraded }}{\text { Weight of diesel oil present originally }} \times 100$

Where, the weight of diesel oil degraded $=$ original weight of diesel oil - weight of residual diesel oil obtained after evaporating the extractant.

\section{Standard Plate Count of Oil Degrading Microorganisms}

The number of oil-degrading microorganisms from each experimental pot soil after completion of their treatment of time period interval was determined by the standard plate count method for viable cells as described (Margesin \& Schinner 1999b), using oil agar plates (minimal medium) with $1 \%$ diesel oil as the sole source of carbon. Ten $g$ of the diesel contaminated soil samples along with control were weighed and then added in $100 \mathrm{~mL}$ sterile distilled water. Serial dilutions of the soil samples were prepared up to $10^{-6}$. A $0.1 \mathrm{~mL}$ of appropriate dilution was plated in above mentioned medium plates by spread plate method. Enumerations were made with triplicates. Colony-forming units (cfu) were counted after 7 days at $28^{\circ} \mathrm{C}$. No significant growth was observed on control plates without diesel oil. Some oil-degrading fungi and actinomycetes producing maximum zone of hydrolysis around the colony were observed during this soil bioremediation experiment.

\section{Germination and Plantation Tests in Soil During Bioremediation Treatment of Soil Contaminated with Diesel Oil}

After fifty days of bioremediation treatment of soil contaminated with diesel oil was used to check that which quality of soil is appropriate for the plantation. In our study, Vigna radiata (Green gram or mung) was chosen for the seed germination test as it is a fast-growing and common leguminous plant which is available locally also. Healthy and uniform sized seeds of Green gram (Vigna radiata) were taken in sterile Petri plates for washing with sterile distilled water and then surface sterilized in $1 \% \mathrm{HgCl}_{2}$ for about 5 minutes followed by washing in sterile distilled water thrice under the aseptic condition to remove traces of $\mathrm{HgCl}_{2}$. The surface-sterilized 8 seeds were then sowed in each of the 8 experimental pot which contained treated and untreated soil samples, i.e., 1. (S) uncontaminated control soil; 2. (CS) contaminated soil; 3 . (CSF) contaminated soil + N-P-K fertilizer; 4. (CSC) contaminated soil + compost; 5. (CSI) contaminated soil + Inoculum; 6. (CSFI) contaminated soil + N-P-K fertilizer + Inoculum; 7. (CSCI) contaminated soil + compost + Inoculum; 8. (SCSCI) sterile (oil) contaminated soil + compost + Inoculum respectively. After a few days of watering, the germination of the seeds was noted. Growth of the plants, height of the stem, number of leaves and pods were also observed during the plant development. The germination percentage was calculated by the following formula:

Germination $(\%)=\frac{\text { Number of seeds germinated }}{\text { Total number of seeds }} \times 100$

\section{Statistical Analyses}

All results were expressed as the mean \pm standard deviation $( \pm \mathrm{SD})$. The experiment was conducted at least 3 times, and each treatment had 3 replicates. Thus, for most data points, the $n=3$. The Graph Pad PRISM (Version-5) software was used for statistical evaluations. Differences between untreated and treated groups were tested by two-way analysis of 
variance (ANOVA). Differences at $\mathrm{p}<0.001$ were considered highly significant and $\mathrm{p}<0.01$ were considered significant while $\mathrm{p}>0.05$ were considered as non-significant (ns).

\section{RESULTS}

\section{Screening of Lipase Producing Bacteria}

The lipolytic activity of the isolates was determined by measuring the zone of lipid hydrolysis on the tributyrin agar plate. Among the 72 lipolytic isolates, MG2 (pH-7) showed maximum zone of hydrolysis $(2.57 \mathrm{~mm})$ around the colony and was also able to grow at $\mathrm{pH} 9$ with maximum lipase activity $(3.12 \mathrm{~mm})$ which shows its alkali tolerant nature and was selected for further studies.

\section{Identification of Selected Isolate}

The selected bacterium MG2 was negative towards citrate utilization, indole test, methyl red Voges-Proskauer tests, $\mathrm{H}_{2} \mathrm{~S}$ production, urea hydrolysis, oxidase and haemolytic activity test. The strain was catalase positive.

The strain showing the maximum zone of hydrolysis was designated as MG2. Using consensus primers, the $1.5 \mathrm{~kb}$ 16SrDNA fragment was amplified using Taq DNA Polymerase by PCR technique. The morphological, cultural, physiological and biochemical characteristics, as well as phylogenetic trees made using Neighbour Joining method (Saitou \& Nei 1987), suggested that the isolate MG2 was close to a novel bacterium Staphylococcus argenteus. Hence, this strain was identified and named as Staphylococcus argenteus MG2.
The 16S rDNA nucleotide sequence of the isolate Staphylococcus argenteus MG2 determined in this study has been deposited in the (NCBI, US) Gene Bank database under the accession number KY082046. The culture identified as Staphylococcus argenteus MG2 has been deposited in Microbial Type Culture Collection Centre and Gene Bank (MTCC), Institute of Microbial Technology, (IMTECH), Chandigarh, India, under the accession number MTCC12820 (Golani et al. 2019).

\section{Characteristics of the Soil Sample}

The main features of experimental soil analysed were, Sand$69.0(\%)$, Slit- $17.2(\%)$, Clay- $13.8(\%)$, WHC- $50.0(\%)$, CaCO3- 17.6 (\%), Organic- $1.38(\%), \mathrm{pH}-7.5$.

\section{Chemical Analysis}

Soil pH: The soil $\mathrm{pH}$ remained in the neutral to the slightly alkaline range (7-8) during the whole incubation period independent of fertilization which is shown in Fig. 1.

Total petroleum hydrocarbons content (estimation of the percentage of diesel oil): Total petroleum hydrocarbons (TPH) content during the bioremediation trials is reported in Fig. 2. Both treatment and time had a significant influence on the residual hydrocarbon content. When CS was statistically compared for degradation of oil with other treated samples, then $\mathrm{p}$-value was found to be highly significant $(\mathrm{p}<0.001)$ for all. There was a little loss of hydrocarbons (15\%) of CS in the first incubation period i.e. on the 10th day, probably due to hydrocarbon degradation only by the indigenous soil

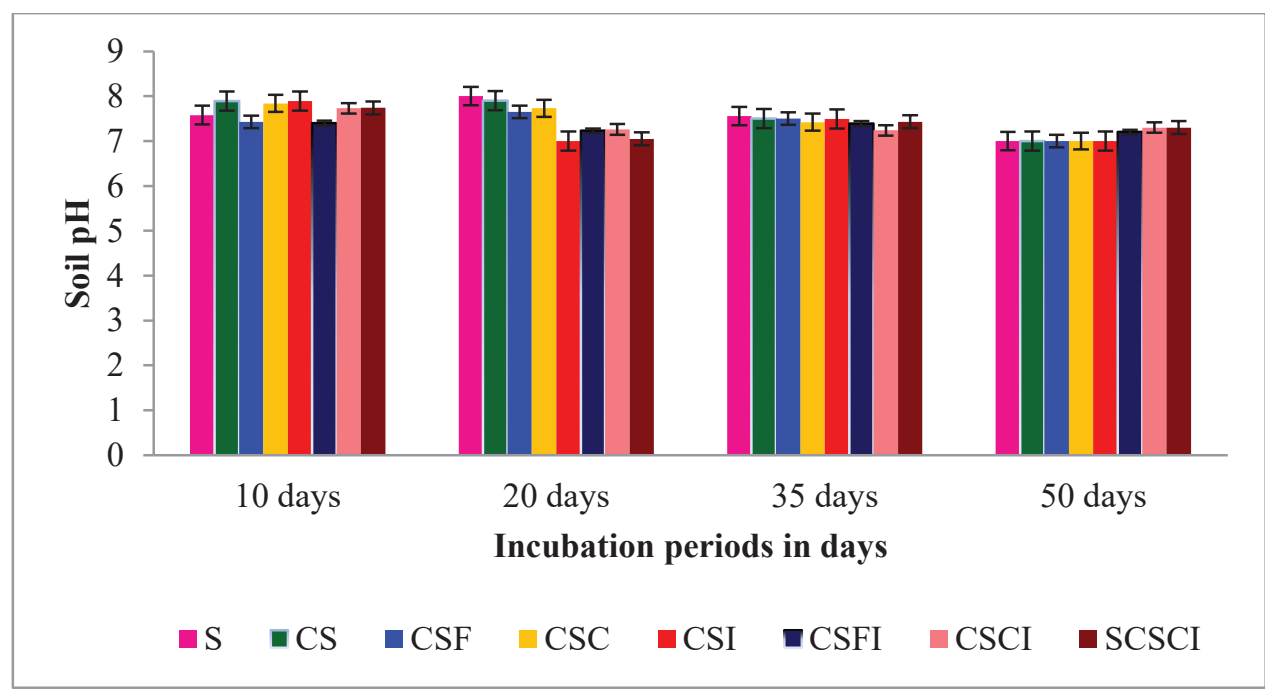

Fig. 1: Soil pH during bioremediation treatment of soil contaminated with diesel oil. 
microorganisms. Such a loss was significantly lower relative to the other trials on the same date. The percentage of oil degradation of biologically treated samples (CSF-52\%, CSC$58 \%$ ) was higher than CS. The difference suggests, since the first incubation phases, biodegradation by a microbial community present in the biologically treated samples was enhanced by the addition of biological nutrients which was significant as compared to natural attenuation. In CSI, the $\%$ of oil degradation was $74.4 \%$ which was significantly higher $(\mathrm{p}<0.001)$ than CSF and CSC because of the addition of inoculum of Staphylococcus argenteus MG2, a potential lipase producing bacterium.

On the contrary, the decrease of TPH was highest for all the biologically active (CSFI-83.10\%, CSCI-83.90\%, SCSCI-84.10\%) samples with the inoculum of Staphylococcus argenteus MG2. The oil degradation by Staphylococcus argenteus MG2 was not surprising not only because it was isolated from oil-spilled soil, but also because it is known to possess a more competent and active hydrocarbon degrading enzyme system. It is known to be fast-growing and is capable of degrading a wide variety of organic compounds. This biodegradation was also enhanced by a microbial community present in the biologically treated samples due to the addition of biological nutrients in CSFI and CSCI while in SCSCI the oil degradation by Staphylococcus argenteus MG2, a potential lipase producing bacterium, was found to be more competent and addition of compost also enhanced its activity.

On the 50th day, CS (32\%) and CSF (70.8\%), CSC (75\%) was not significantly different either for initial or final TPH concentrations. The occurrence that CSF, CSC treatment presented an effect comparable to that in the contaminated but untreated soil, suggests a poor contribution of nutrients added to the soil in stimulating the indigenous microbial community. Probably, CSF and CSC treatment would have been more effective if nutrients had been added to the soil periodically rather than only at the initial experimental phase. In CSI treatment, the final biodegradation of oil was $84.4 \%$ because of the addition of inoculum of Staphylococcus argenteus $\mathrm{MG} 2$.

After 50th day, SCSCI treatment presented the lowest TPH concentration, corresponding to a TPH degradation of $94 \%$, which was slightly higher than that of CSCI (93\%) \& CSFI (91\%) which concludes the most effective biotreatment in hydrocarbon decay and confirms that the Staphylococcus argenteus MG2 is a potential lipase producing bacterium for the degradation of TPH. The compost may have facilitated the degradation of TPH because it plays an important role in supplementing continuously nutrient and carbon sources. Overall results indicated that the degradation of TPH was faster in all the inoculum added treated soil samples than others.

Standard plate count of oil degrading microorganisms on diesel oil agar plate: The number of oil-degrading microorganisms from each experimental pot soil after completion of their treatment of time period interval was determined by the standard plate count method for viable cells as described

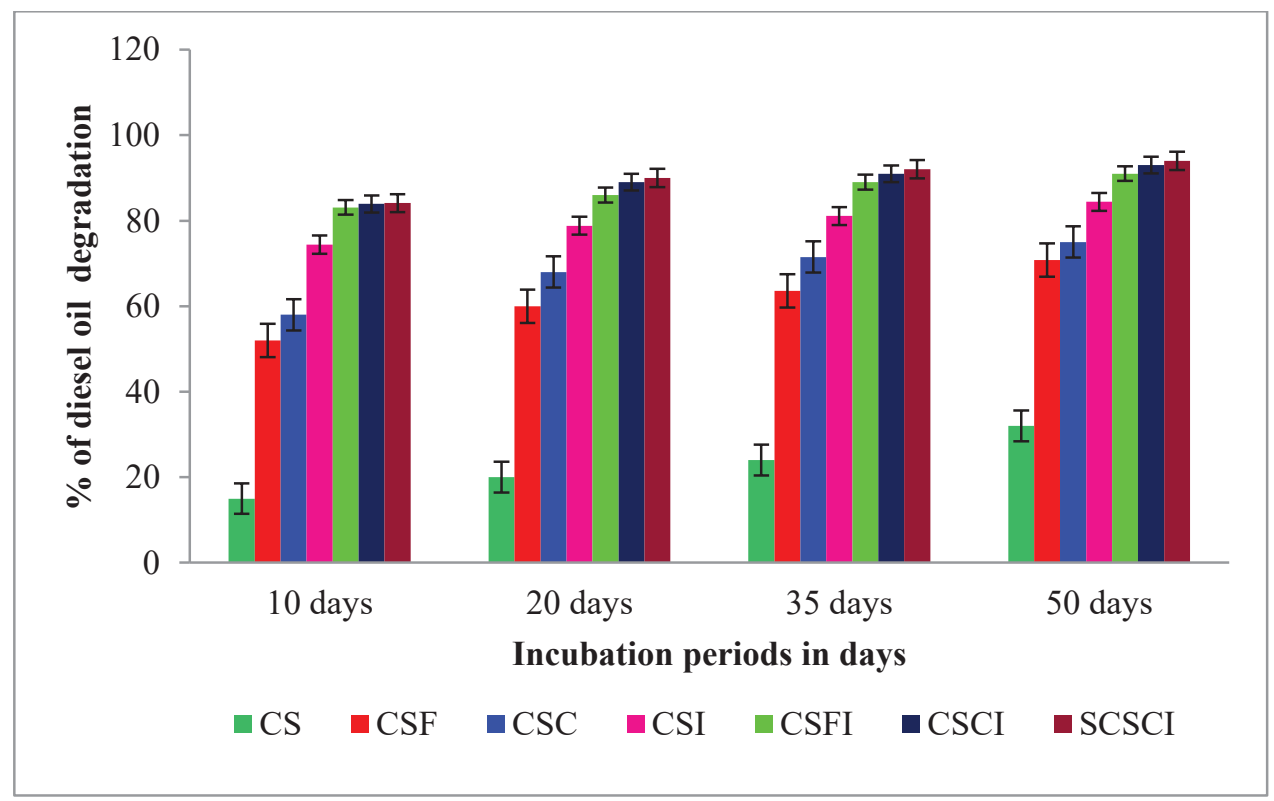

Fig. 2: Percentage of diesel oil degradation during bioremediation treatment of soil contaminated with diesel oil ( $10 \mathrm{~g} / \mathrm{kg}$ soil) in $50 \mathrm{days}(\mathrm{p}<0.001)$. 
(Margesin \& Schinner 1999b), using oil agar plates with $1 \%$ diesel oil as the sole source of carbon. Microbial count on diesel oil agar plate during the bioremediation trials are reported in Figs. 3 and 4. The oil-degrading microbial count in (S) uncontaminated control soil was found to be lesser via out the incubation period than CS, CSF and CSC because S was not contaminated by diesel oil which provides carbon source for microorganisms to grow.

Microbial community present in the biologically treated samples was enhanced by the addition of biological nutrients.
In CSI the number of oil-degrading microorganisms was higher than CS, CSF and CSC because of the addition of inoculum of Staphylococcus argenteus MG2.

On the contrary, the oil-degrading microbial count was higher for the biologically active samples (CSFI, CSCI) which were inoculated with Staphylococcus argenteus MG2. This microbial count was also higher because of the microbial community present in the biologically treated samples due to the addition of biological nutrients in CSFI and CSCI while in SCSCI treatment the oil-degrading microbial count was

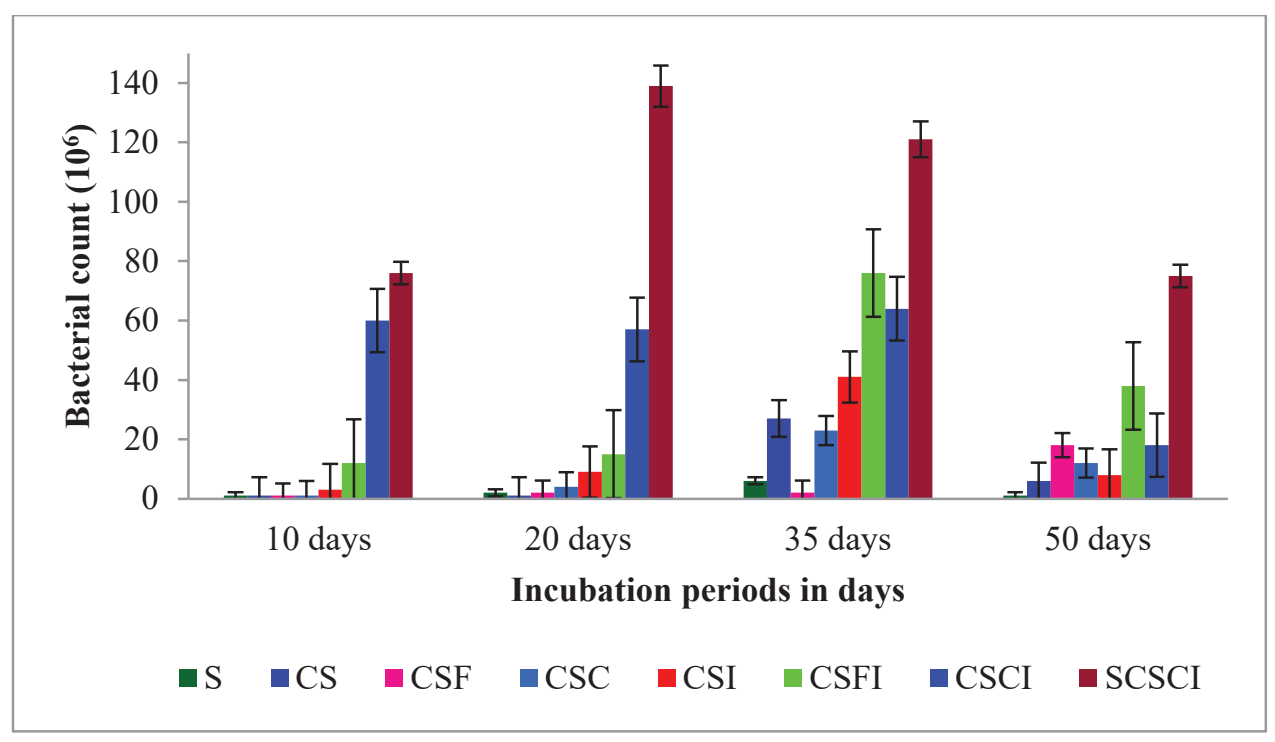

Fig. 3: Oil degrading bacterial count (CFU/g of soil) on diesel oil agar plate during bioremediation treatment of soil contaminated with diesel oil.

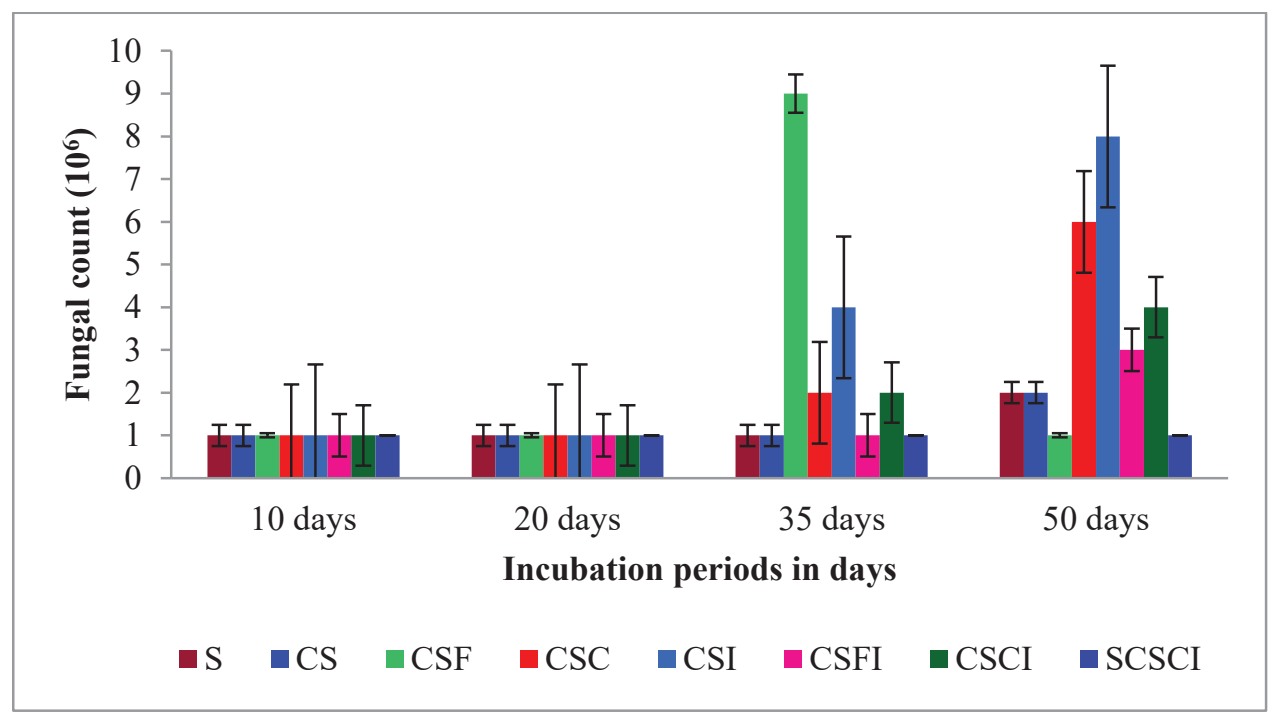

Fig. 4: Oil degrading fungal count (CFU/g of soil) on diesel oil agar plate during bioremediation treatment of soil contaminated with diesel oil. 
Table 1: Effect of bioremediation treatment of soil contaminated with diesel oil on the growth of plant of Vigna radiata.

\begin{tabular}{|lllllll|}
\hline $\begin{array}{l}\text { S. } \\
\text { No. }\end{array}$ & Soil sample & $\begin{array}{l}\text { Seed germina- } \\
\text { tion }(\%)\end{array}$ & $\begin{array}{l}\text { No. of } \\
\text { plants }\end{array}$ & $\begin{array}{l}\text { Average height of plants } \\
\text { (feet) a, b, c, d }\end{array}$ & $\begin{array}{l}\text { Average No. of leaves } \\
\text { a, b, c, d }\end{array}$ \\
\hline 1 & S & 100 & 8 & $7.053 \pm 0.050$ & $41 \pm 1$ & 0 \\
$2, \mathrm{~b}, \mathrm{c}, \mathrm{d}$
\end{tabular}

a. The results are expressed as the mean \pm SD of three independent experiments conducted in triplicates.

b. Differences between untreated and treated growth of plants were tested by two-way analysis of variance (Anova).

c. differences at ***, $\mathrm{p}<0.001$ were considered highly significant and $* *, \mathrm{p}<0.01$ were considered significant and $\mathrm{p}>0.05$ were considered as non-significant (ns)

d. ANOVA was performed taking $\mathrm{S}$ as a control for all the observations.

highest than all other samples because of the inoculation of potential oil-degrading Staphylococcus argenteus MG2. It is known to be fast growing in oil-contaminated soil and is capable of degrading a wide variety of organic compounds. Addition of compost also played an important role in supplementing continuously nutrient and carbon sources. It was also observed during the whole experiment that the microbial growth in SCSCI appeared in 2 days while other soil samples required 4-5 days. It was also noted that the fungal count was not found to be significant than bacterial count. Microbial growth was found to be good in SCSCI which was followed by CSCI and CSFI respectively.

Germination and plantation tests in soil during bioremediation treatment of soil contaminated with diesel oil: After fifty days of bioremediation treatment of soil contaminated with diesel oil was used to check that which quality of soil is appropriate for the germination of seeds and growth of plant. Vigna radiata (Green gram or mung) was chosen for the seed germination test. The surface-sterilized 8 seeds were then sowed in each experimental pot ( 8 in number) which contained treated and untreated soil samples, i.e., 1. (S) uncontaminated control soil; 2. (CS) contaminated soil; 3. (CSF) contaminated soil + N-P-K fertilizer; 4. (CSC) contaminated soil + compost; 5 . (CSI) contaminated soil + Inoculum; 6. (CSFI) contaminated soil $+\mathrm{N}-\mathrm{P}-\mathrm{K}$ fertilizer + Inoculum; 7. (CSCI) contaminated soil + compost + Inoculum; 8. (SCSCI) sterile (oil) contaminated soil + compost + Inoculum respectively.

The present investigation led to the preliminary assessment and comparison of effect in treated and untreated samples by the germination test. The germination percentage (Table 1) in the 1. (S) was $100 \%$ while in 2. (CS) the ger- mination percentage was 50\%. In 3. (CSF) and 5. (CSI), the germination percentage was also $50 \%$ while in 4 . (CSC) percentage was $62.5 \%$. The germination percentage in 6 . (CSFI) was $62.5 \%$ while in 7 . (CSCI) was $87.5 \%$. In 8 . (SCSCI) the seed germination percentage was $100 \%$.

Growth of the plant, height of the plant, and the number of leaves and pods were also observed during the plant development in various soil samples which is shown in Fig. 5.

Effect of bioremediation treatment of soil contaminated with diesel oil on the growth of plant of Vigna radiata is reported in Table 1. Results were similar to the germination of seeds. When $\mathrm{S}$ was statistically compared for growth of the plant with other treated samples, then $\mathrm{p}$-value was found to be highly significant $(\mathrm{p}<0.001)$ for SCSCI except the height of plant (ns).

\section{DISCUSSION}

Overall results of biotreatment in hydrocarbon decay indicated that the degradation of TPH was faster in all the Staphylococcus argenteus MG2 inoculum added treated soil samples than others. The compost may have facilitated the degradation of TPH because it plays an important role in supplementing continuously nutrient and carbon sources. The result agrees with the studies of Namkoong et al. (2000) and Riffaldi et al. (2006) who found that the degradation of TPH was significantly enhanced by the addition of organic amendments. Margesin et al. (1999) reported that after 116 days, the initial hydrocarbon contamination of $5 \mathrm{mg} / \mathrm{g}$ soil dry weight got reduced to 1.15 and $0.538 \mathrm{mg} / \mathrm{g}$ soil dry weight in the unfertilized and fertilized soil, respectively. This correlates to decontamination percentages of 77 and $89 \%$, 


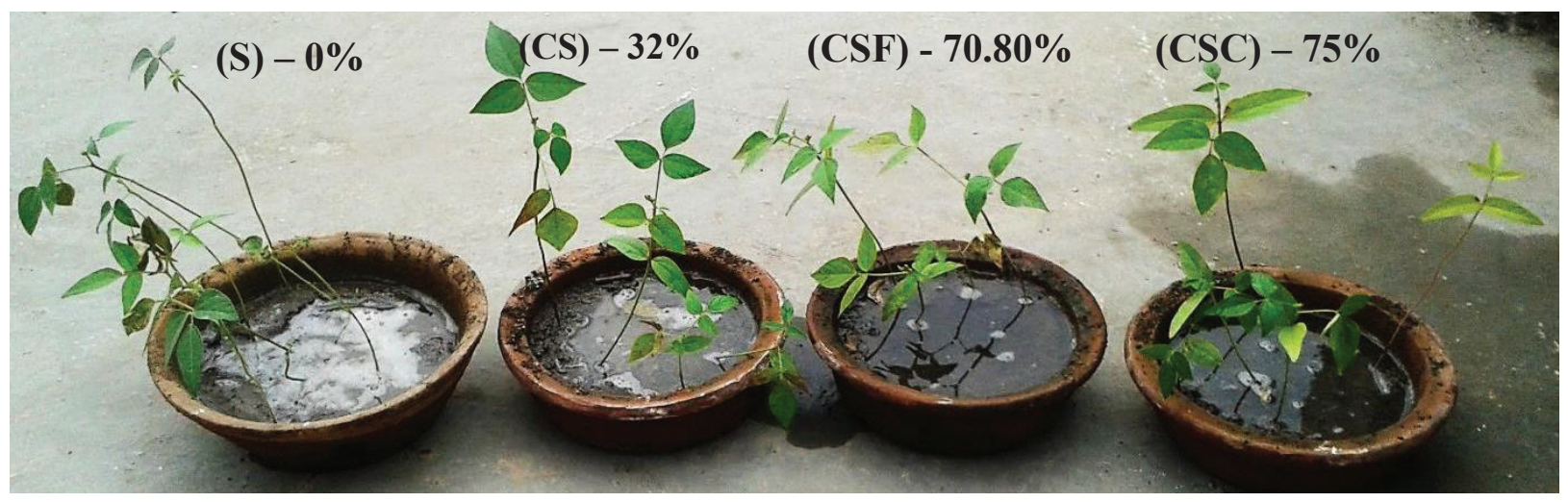

(a)

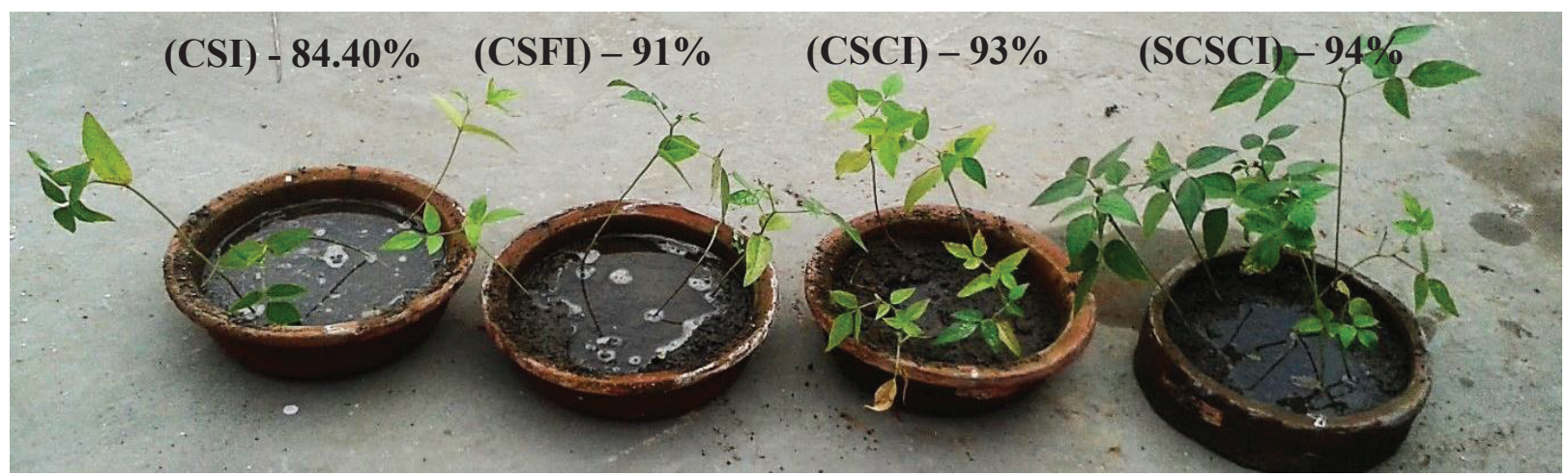

(b)

Fig. 5: (a), (b) Growth of the plant Vigna radiata during bioremediation treatment of soil contaminated with diesel oil.

respectively. In our results, after 50th day, SCSCI treatment corresponds to a TPH degradation of $94 \%$, which was higher than the earlier mentioned results.

The biostimulation resulted in increased counts of oil degraders significantly. Margesin et al. (1999) observed that bioremediation treatment by adding inorganic nutrients enhanced hydrocarbon degradation by the indigenous soil microorganisms significantly as compared to natural attenuation. Our results are in accordance to Margesin et al. (2001) who concluded that in the fertilized soil all biological parameters (microbial numbers and lipase activity) got enhanced and correlated significantly with each other as well as with the residual hydrocarbon concentration which shows the importance of biodegradation. The effect of biostimulation of the indigenous soil microorganisms reduced with time. The microbial activities in the unfertilized soil fluctuated around background levels during the whole study.

A germination and plantation test in the soil during bioremediation treatment of soil contaminated with diesel oil was performed to check that which quality of soil is appropriate for the germination of seeds and growth of Vigna radiata (Green gram or mung) plant. The germination percentage in the 1 . (S) was $100 \%$ because it was not contaminated with oil while in 2. (CS) the germination percentage was found to be $50 \%$ which clearly indicates that the contamination of oil in soil inhibits the germination of seeds. In 3. (CSF) and 5. (CSI), the germination percentage was also $50 \%$ while in 4. (CSC) percentage was found to be $62.5 \%$. These results reveal that the addition of compost provides nutrients to the soil required for germination of seeds. The germination percentage in 6 . (CSFI) was $62.5 \%$ while in 7 . (CSCI) was $87.5 \%$ which clearly shows that the addition of compost and inoculation of Staphylococcus argenteus MG2 enhanced the seed germination percentage. In 8. (SCSCI) the seed germination percentage was $100 \%$. It means that not only the addition of compost provides nutrients but also the inoculation of potential oil-degrading bacteria Staphylococcus argenteus MG2 degrades oil and thereby releases simple fatty acids which enhanced the seed germination percentage. Initially, the growth of plants was found to be good in (S) uncontam- 
inated control soil but after 1.5 months the deterioration of plants was fast than other samples and number of pods was zero because no one fertilizer or compost was added in soil. The number of plants, leaves and pods was found to be higher in SCSCI soil sample followed by CSCI soil sample.

Similar results were obtained by other scientists when the experiment was performed in selected plants such as winter wheat, soybean and sunflower. Growth parameters such as germination percentage, fresh weight and plant height were observed (Yanqing et al. 2012).

From the results obtained above, it can be understood that biostimulation can effectively be used to combat pollution. The findings of other researchers also support the fact that biostimulation could indeed be a solution for degrading environmental pollutants (Miller 2010).

\section{CONCLUSION}

To conclude, the results confirmed that the bioremediation mediated by Staphylococcus argenteus MG2 from SCSCSI (sterile oil-contaminated soil + compost + inoculum) sample and CSCSI have been very effective and the degradation of TPH was significantly enhanced by the treatment with compost and can be used to reclaim the oil-contaminated soil for agricultural purpose in the oil-contaminated soil.

The above experiment indicates that bioremediation can be used effectively to treat oil-contaminated soil. Bioremediation usually lowers the costs as compared to chemical treatment processes for various contaminated sites. It is also less disturbing to the environment. The present study has shown that the Staphylococcus argenteus MG2 bacteria isolated from the oil-spilled site possess the capacity to produce lipase, therefore it was used for the degradation of oil-contaminated soil. The effectiveness of the bioremediation was studied by finding out the germination percentage of a fast growing leguminous plant (Vigna radiata). It was observed that the germination percentage in the treated soil was notably greater. The results also prove that biostimulation is an effective method of reducing the environmental pollution. Thus, the present study concludes that microbial degradation can be regarded as a key component in the clean-up strategy for petroleum hydrocarbon remediation.

\section{ACKNOWLEDGEMENT}

The financial assistance provided by University Grant Commission, Bhopal (MS-29/103042/12-13/CRO) and facilities provided by the Management \& Principal of PMB Gujarati Science College and School of Life Sciences, DAVV, Indore is gratefully acknowledged.

\section{REFERENCES}

Arulazhagan, P. and Vasudevan, N. 2011. Role of nutrients in the utilization of polycyclic aromatic hydrocarbons by halotolerant bacterial strain. J. Environ. Sci., 23: 282-287.

Atlas, R.M. 1981. Microbial degradation of petroleum hydrocarbons: An environmental perspective. Microbiol. Rev., 45: 180-209.

Cerniglia, C.E. and Sutherland, J.B. 2010. Degradation of polycyclic aromatic hydrocarbons by fungi. In: Handbook of Hydrocarbon and Lipid Microbiology, pp. 2079-2110.

Chan, S.M.N., Luan, T., Wong, M.H. and Tam, N.F.Y. 2006. Removal and biodegradation of polycyclic aromatic hydrocarbons by Selenastrum capricornutum. Environ. Toxicol. Chem., 25: 1772-1779.

Chang, R. 1998. Chemistry, 6th Ed., McGraw Hill Company, Inc., pp. 962-963.

Chithra, S. and Shenpagam, N.H. 2014. Isolation and identification of oil degrading bacteria from oil contaminated soil and comparison of their bioremediation potential. Global J. for Res. Analysis, 3: 181-184.

Golani, M., Hajela, K. and Pandey, G.P. 2019. Isolation and identification of a novel lipase producing Staphylococcus argenteus MG2 bacterium from oil spilled soil. Int. J. of Advance and Innovative Research, 6(1) (XIV): 20-30.

Hadibarata, T. and Tachibana, S. 2009. Microbial degradation of n-eicosane by filamentous fungi. In: Interdisciplinary Studies on Environmental Chemistry and Environmental Research in Asia. (Eds. Y. Obayashi, T. Isobe, A. Subramanian, S. Suzuki and S. Tanabe) Terrapub Tokyo, pp. 323-329.

Hamamura, N., Ward, D.M. and Inskeep, W.P. 2013. Effects of petroleum mixture types on soil bacterial population dynamics associated with the biodegradation of hydrocarbons in soil environments. FEMS Microbiol. Ecol., 85: 168-178.

Holt, J.G., Krieg, N.R., Sneath, P.H.A., Staley, J.T. and Williams. S.T. 1994. Bergey's Manual of Determinative Bacteriology. Ninth Edition, Williams and Wilkins Baltimore, Group 17, Gram-Positive Cocci, pp. 527-558.

Lin, J.F., Lin, Q., Li, J., Fei, Z.A., Li, X.R., Xu, H., Qiao, D.R. and Cao, Y. 2012. Bacterial diversity of lipase-producing strains in different soils in southwest of China and characteristics of lipase. Afr. J. Microbiol. Res., 6(16): 3797-3806.

Margesin, R. and Schinner, F. 1999a. Biological decontamination of oil spills in cold environments. J. Chem. Technol. Biotechnol., 74: 1-9.

Margesin, R. and Schinner, F. 2001. Bioremediation (natural attenuation and biostimulation) of diesel oil contaminated soil in an alpine glacier sking area. Appl. Env. Microbiol., 67: 3127-3133.

Margesin, R. and Schinner, F. 1999b. A feasibility study for the in situ remediation of a former tank farm. World J. Microbiol. Biotechnol., 15: 615-622

Margesin, R., Zimmerbauer, A. and Schinner, F. 1999. Soil lipase activity-a useful indicator of oil biodegradation. Biotech. Techniques, 13: 859-863.

Marquez-Rocha, F.J., Hernandez-Rodriguez, V. and Lamela, M.T. 2001. Biodegradation of diesel oil in soil by a microbial consortium. Water Air Soil Pollut., 128: 313-320.

Miller, H. 2010. Biostimulation as a form of bioremediation of soil pollutants. MMG 445 Basic Biotechnology, eJournal, 6(1): 7-12.

Morgan, P. and Watkinson, R.J. 1989. Hydrocarbon degradation in soils and methods for soil biotreatment. Crit. Rev. Biotechnol., 8: 305-333.

Munoz, R., Guieysse, B. and Mattiasson, B. 2003. Phenanthrene biodegradation by an algal-bacterial consortium in two-phase partitioning bioreactors. Appl. Microbiol. Biotechnol., 61: 261-267. 
Nakamura, K.M., Yoda and Fukase, T. 1994. Treatment process for drainage containing fats and oils. Japan Patent. JP-06246295.

Namkoong, W., Hwang, E.Y., Park, J.S. and Choi, J. K. 2002. Bioremediation of diesel contaminated soil with composting. Environ. Pollut., 119: 23-31.

Norris, R.D. 1994. Handbook of Bioremediation. CRC Press Boca Raton Fla.

Riffaldi, R., Levi-Minzi, R., Cardelli, R., Palumbo, S. and Saviozzi, A. 2006. Soil biological activities in monitoring the bioremediation of diesel oil-contaminated soil. Journal Water, Air, and Soil Pollution, 170: 3-15.

Saitou, N. and Nei, M. 1987. The neighbour-joining method: A new method for reconstructing phylogenetic trees. Molecular Biology and Evolution, 4: 406-425.

Thilakar, J.R. and Rathi, J.J. 2013. Bioremediation of diesel contaminated soil by oil degrading bacteria (Pseudomonas sp.) using biostimulation method. J. Microbiol. Biotech. Res., 3(5): 18-26.

Van Gestel, K., Mergaert, J., Swings, J. and Coosemans, J. 2003. Bioremediation of diesel oil contaminated soil by composting with biowaste. Environ. Pollut., 125: 361-368.

Vasanthavigar, M., Srinivasamoorthy, K., Ganthi, R.R., Vijayaraghavan, K. and Sarma, V.S., 2010. Characterisation and quality assessment of groundwater with a special emphasis on irrigation utility: Thirumanimuttar sub-basin, Tamil Nadu, India. Arabian Journal of Geosciences, 5(2): 245-258.

Yanqing, Z., Ziling, S., Jianping, C., Cui, L., Bo, Q. and Qinghai, W. 2012. Effects of oil-contaminated soil on the seed germination and seedling growth of selected crops. World Automation Congress (WAC). IEEE Conference Publications, 1-4. 